\title{
Does neighborhood size really cause the word length effect?
}

\author{
Dominic Guitard $^{1} \cdot$ Jean Saint-Aubin $^{1} \cdot$ Gerald Tehan $^{2} \cdot$ Anne Tolan $^{3}$
}

Published online: 10 October 2017

(C) Psychonomic Society, Inc. 2017

\begin{abstract}
In short-term serial recall, it is well-known that short words are remembered better than long words. This word length effect has been the cornerstone of the working memory model and a benchmark effect that all models of immediate memory should account for. Currently, there is no consensus as to what determines the word length effect. Jalbert and colleagues (Jalbert, Neath, Bireta, \& Surprenant, 2011a; Jalbert, Neath, \& Surprenant, 2011b) suggested that neighborhood size is one causal factor. In six experiments we systematically examined their suggestion. In Experiment 1, with an immediate serial recall task, multiple word lengths, and a large pool of words controlled for neighborhood size, the typical word length effect was present. In Experiments 2 and 3, with an order reconstruction task and words with either many or few neighbors, we observed the typical word length effect. In Experiment 4 we tested the hypothesis that the previous abolition of the word length effect when neighborhood size was controlled was due to a confounded factor: frequency of orthographic structure. As predicted, we reversed the word length effect when using short words with less frequent orthographic structures than the long words, as was done in both of Jalbert et al.'s studies. In Experiments 5 and 6, we again observed the typical word length effect, even if we controlled for neighborhood size and frequency of orthographic structure. Overall, the results were not consistent with the predictions
\end{abstract}

Jean Saint-Aubin

jean.saint-aubin@umoncton.ca

1 École de psychologie, Université de Moncton, Moncton, New Brunswick E1A 3E9, Canada

2 University of Southern Queensland, Toowoomba, Queensland, Australia

3 Australian Catholic University, Brisbane, Queensland, Australia of Jalbert et al. and clearly showed a large and reliable word length effect after controlling for neighborhood size.

Keywords Working memory $\cdot$ Word length effect $\cdot$ Immediate serial recall

In immediate serial recall, it is well established that participants are better at recalling verbatim a list of short words (e.g., $d o g$, blue, man) than a list of long words (e.g., giraffe, subway, lemon). This phenomenon, known as the word length effect, has been the cornerstone of the working memory model (Baddeley, 2000; Baddeley \& Hitch, 1974) and the most important evidence in support of decay models (e.g., Brown \& Hulme, 1995; Burgess \& Hitch, 1999; Cowan, 1995). In 1975, Baddeley, Thomson, and Buchanan demonstrated two different word length effects. The first was based on the pronunciation time (time-based), an advantage for words that can be rehearsed faster than other words of similar length. The second was based on the length (syllable-based), an advantage for words with fewer syllables. Subsequent studies have shown that the time-based word length effect was restricted to the stimuli used in Baddeley, Thomson, and Buchanan's original demonstration, since it has been replicated many times with the original stimuli (e.g., Cowan et al., 1992; Longoni, Richardson, \& Aiello, 1993; Nairne, Neath, \& Serra, 1997), but has never been observed with other sets of stimuli (e.g., Lovatt, Avons, \& Masterson, 2000; Neath, Bireta, \& Surprenant, 2003). In contrast, the syllable-based word length effect is a robust phenomenon that has been replicated in numerous studies and languages with a variety of stimuli, memory tasks (immediate serial recall, span or order reconstruction), presentation modalities (visual or oral), and response modalities (oral, written, clicking, or picture selection) (e.g., Beaman, Neath, \& Surprenant, 2008; Cowan, Baddeley, 
Elliott, \& Norris, 2003; Hulme, Silvester, Smith, \& Muir, 1986; Hulme, Thomson, Muir, \& Lawrence, 1984; Guérard, Saint-Aubin, Burns, \& Chamberland, 2012; LaPointe \& Engle, 1990; Poirier, Schweickert, \& Oliver, 2005; Service, 1998; Wilson \& Emmorey, 1998). Initially, the word length effect was accounted for by calling upon rehearsal mechanisms (Baddeley \& Hitch, 1974). However, different mechanisms have subsequently been put forward. For instance, proposed causal factors include output delays (Cowan et al., 1992; Cowan, Wood, \& Borne, 1994b), reconstruction errors (Neath \& Nairne, 1995), differential decay (Brown \& Hulme, 1995; Page \& Norris, 1998), and item distinctiveness (Brown, Neath, \& Chater, 2007). At present there is no consensus as to what determines the word length effect, and a new factor has even been proposed (Jalbert, Neath, Bireta, \& Surprenant, 2011 a; Jalbert, Neath, \& Surprenant, 2011 b; for convenience, referred to hereafter as Jalbert et al., 2011a and $\mathrm{b}$, respectively): Jalbert and colleagues suggested that neighborhood size could account for the syllable-based word length effect. The present study was aimed at providing a new, comprehensive investigation of this important account.

Over the years it has become increasingly clear that shortterm ordered recall is influenced by a number of factors beyond word length (e.g., Guérard \& Saint-Aubin, 2012; Hulme, Maughan, \& Brown, 1991; Poirier \& Saint-Aubin, 1996; Walker \& Hulme, 1999; Watkins \& Watkins, 1977). To control for as many confounding variables as possible, short and long words are typically matched on such characteristics as imageability, frequency of usage, and degree of phonological overlap. However, until recently, neighborhood size has not been identified as a control variable (Roodenrys, Hulme, Lethbridge, Hinton, \& Nimmo, 2002). A neighbor of a word can be defined as a word that differs from the target word by only one letter (orthographic neighborhood) or one phoneme (phonological neighborhood) (see Coltheart, Besner, Jonasson, \& Davelaar, 1979; Luce \& Pisoni, 1998). For instance, the orthographic neighbors of the word rat include such words as bat, fat, ran, rap, rot, and rut.

In short-term ordered recall, words with more orthographic neighbors are recalled better than words with fewer neighbors. This phenomenon, known as the neighborhood effect, is now well-established and has been observed in both English and French (Allen \& Hulme, 2006; Clarkson, Roodenrys, Miller, \& Hulme, 2017; Derraugh, Neath, Surprenant, Beaudry, \& Saint-Aubin, 2017 ; Glanc \& Greene, 2012 ; Jalbert et al., 2011a, b; Roodenrys et al., 2002). It is generally assumed that orthographic neighbors contribute to recall performance by enhancing the efficiency of the redintegrative process (see, e.g., Derraugh et al., 2017; Roodenrys, 2009). In broad strokes, at recall, the representations of list items are likely to be degraded. These degraded representations would undergo a reconstruction process based on long-term knowledge. Orthographic neighbors of the degraded trace would be in a more active state than other lexical representations because of their shared activation with the to-be-remembered item. Because of interactive associations, the lexical representation of the target word is likely to be the most active, because essentially it can be viewed as the average of its neighbors. Consequently, words with many neighbors should be recalled better than words with few neighbors. Interestingly, word length naturally covaries with neighborhood size. For instance, in English, using the MRC database and the MCWord database of Medler and Binder (2005), we found that on average, four-letter, one-syllable words have 8.31 neighbors, whereas seven-letter, three-syllable words have 0.32 neighbors. Similarly, in French using Lexique, we found that on average, four-letter, one-syllable words have 8.37 neighbors, whereas seven-letter, three-syllable words have 1.34 neighbors (New, Pallier, Brysbaert, \& Ferrand, 2004).

Not surprisingly, Jalbert et al. (2011a, b) showed that in all previous studies of the syllable-based word length effect, neighborhood size was a confounded factor, with short words having systematically more orthographic neighbors than long words. Jalbert and her colleagues explored the relationship between neighborhood size and word length with both words (Jalbert et al., 2011a) and nonwords (Jalbert et al., 2011b). These articles made three points. First, the manipulation of syllable length in previous studies of the word length effect has always been confounded with neighborhood size. Second, the factors that modulate the word length effect produce identical effects on neighborhood size. For example, both the word length effect and the neighborhood size effect are abolished under articulatory suppression (Jalbert et al., 2011b). Third, the most compelling findings have involved matching oneand three-syllable words on neighborhood size (Jalbert et al., $2011 \mathrm{a}, \mathrm{b})$ or factorially manipulating neighborhood size and word length. Word length effects were not observed when neighborhood size was equated for short and long items. When syllable length and neighborhood size were factorially manipulated in nonwords (Jalbert et al., 2011b), the effects of neighborhood size were readily apparent, but syllable length had no influence on performance. These three lines of evidence provide a strong case for the neighborhood size explanation for the word length effect.

The role of nonpresented items (orthographic neighbors) in producing the word length effect has important theoretical implications. For instance, it immediately eliminates rehearsal as a causal mechanism for the word length effect. Those results also seriously put in question the utility of explaining the word length effects in terms of item-specific characteristics such as differential decay (Brown \& Hulme, 1995) or assembly errors (Neath \& Nairne, 1995).

Although the Jalbert et al. (2011a, b) studies have created a new way of modeling the word length effect, a number of issues warrant further investigation. The most important of these is the risk of introducing a new confounded factor while 
controlling for neighborhood size. Jalbert et al. (2011a) used one- and three-syllable words that had only one or two orthographic neighbors. Although it is common for three-syllable words to have only one or two neighbors, this situation is exceptional for one-syllable words. In effect, according to the MRC database, in English, only 13\% of four-letter, onesyllable nouns have fewer than three neighbors, whereas this percentage reaches $98 \%$ for seven-letter, three-syllable nouns. The short words used by Jalbert et al. (2011a) are therefore at risk of being nonrepresentative of one-syllable words, which typically have far more neighbors. In fact, one-syllable words with only one or two neighbors are likely to have other peculiar characteristics, such as an unusual orthographic structure. For example, the structures of the words joke, pain, sale, rose, and beam (words with many neighbors, used in Exps. 1a and $1 \mathrm{~b}$ of Jalbert et al., 2011a, in which word length was confounded with neighborhood size) are more common than the structures of the words shriek, grief, birch, gloom, and tweed (words with one or two neighbors, used in Exps. 3 and 4 of Jalbert et al., 2011a, in conditions controlling for neighborhood size). As will be seen below, in the present series of experiments, we took great care to avoid including words with atypical orthographic structures.

Given the limited number of short words with few neighbors and the added difficulty of controlling for other factors such as frequency and imageability, Jalbert et al. (2011a) used a word pool of less than 15 items for each word length. As was mentioned above with the famous study of Baddeley et al. (1975), the investigation of the word length effect has been plagued by the use of small word pools. It could be argued that Jalbert et al. (2011a, b) overcame this issue by using three different sets of materials. Nevertheless, their systematic usage of closed pools can still be considered suboptimal, because the word length effect influences both item and order information (e.g., Mora \& Camos, 2013; Morra, 2015), whereas closed pools mostly capture order information (Neath, 1997). Consequently, the observed abolition of the word length effect by Jalbert and colleagues can be restricted to the order dimension and a substantial word length effect can remain on the item dimension.

Our objective was to determine if neighborhood size causes the word length effect after overcoming the limitations found in the original demonstrations by Jalbert et al. (2011a, b). In Experiment 1, the participants performed an immediate serial recall task and we used five large representative word pools varying in syllable length, while controlling for neighborhood size. In Experiments 2-6, the participants performed an order reconstruction task to control for the influence of output time. In Experiment 2 we used words with many neighbors, whereas in Experiments 3-6 we used words with few neighbors. In Experiment 4, using unigram, bigram, trigram frequency and count, we compared short words with an unusual orthographic structure to long words with a typical orthographic structure.
In Experiments 5 and 6 we controlled for unigram, bigram and trigram count and frequency.

\section{Experiment 1}

The first experiment was designed to replicate Jalbert et al.'s (2011a) study while using large word pools that are more typical of the populations from which they come, and to examine a greater range of word lengths. More precisely, we systematically varied word length from one to five syllables. We included two word pools (one and two syllables) with many neighbors, and three word pools with few neighbors (two, three, and four/five syllables). If neighborhood size is the driving force in the word length effect, then the onesyllable and two-syllable lists with many neighbors should be recalled better than the other lists with few neighbors. In addition, there should be no difference between the one- and two-syllable lists with many neighbors, nor between the two-, three-, and four-/five-syllable lists with few neighbors.

\section{Method}

Participants Sixty-three undergraduate students from the University of Southern Queensland volunteered to participate in the present study. All participants reported normal or corrected-to-normal vision and were native English speakers.

Materials The MRC database was initially used to select the items for the study (www.psy.uwa.edu.au/mrcdatabase/uwa mrc.htm). The selection criterion was that all items had to be concrete nouns and to this end a cut point of 400 (out of 700) was set as the lower limit. Of this overall pool, separate pools were created for four-letter, one-syllable words; six-letter, two-syllable words; three-syllable words; and combined four- and five-syllable words. All words were then submitted to the MCword database (Medler \& Binder, 2005) to obtain estimates of word frequency and neighborhood size. The final pools involved 234 four-letter, one-syllable words, 51 six-letter, two-syllable words with many neighbors, 83 six-letter, two-syllable words with few neighbors, 108 three-syllable words, and 56 four- or five-syllable words. The characteristics of the word pools are presented in Table 3. As can be seen in that appendix, the word pools were matched on word frequency and imageability, and there was no overlap between the large (3 to 19) and small (0 to 2$)$ neighborhood sizes. The one-syllable words ranged from having three to 19 neighbors, and the two-syllable large-neighborhood pool ranged from three to 12 neighbors. In contrast, the two-syllable smallneighborhood, three-syllable, and four- and five-syllable pools had zero to two neighbors. A one-way analysis of variance (ANOVA) was conducted, with list type as a variable, for word frequency, imageability, orthographic neighbor 
count, and frequency of orthographic neighbors. The results revealed that list types did not differ in terms of word frequency, $F(4,527)=1.20, p=.31$, but they did differ in imageability, $F(4,527)=6.28, p<.001$. Post-hoc comparisons (Tukey HSD) confirmed that all conditions were similar in imageability except the four- and five-syllable pools, which had lower imageability scores than all of the other conditions. In addition, orthographic neighbor count, $F(4,527)=560.00$, $p<.001$, and orthographic neighbor frequency, $F(4,527)=6$. $28, p<.001$, differed significantly across lists. As expected, the two conditions with many neighbors differed significantly from the three conditions with few neighbors, and none of the latter conditions differed from each other. In addition, oneand two-syllable words with many neighbors did not differ in their numbers of neighbors, but the one-syllable words had significantly more frequent neighbors than the twosyllable words.

Design A $5 \times 5$ repeated measures design was implemented with list type (one syllable, large neighborhood size; two syllables, large neighborhood size; two syllables, small neighborhood size; three syllables, small neighborhood size; four or five syllables, small neighborhood size) and serial position (1-5) as variables. Each participant completed one block of 30 experimental trials, with six of the trials using materials from each of the five different word pools. In each case, 30 items from each pool were randomly selected without replacement and then randomly assigned to the five serial positions within each of the six trials. Trial order was randomized for each participant.

Procedure All participants were tested individually in one experimental session lasting approximately $20 \mathrm{~min}$. Participants sat approximately $60 \mathrm{~cm}$ from the screen, on which the items were presented. The experimenter was present throughout the session to ensure compliance with the instructions. The five words were presented at the rate of one word per second (1,000 $\mathrm{ms}$ on, $0 \mathrm{~ms}$ off) in the center of the screen. After the last word had been presented, a recall cue in the form of a row of question marks appeared on the screen. Participants were instructed to recall the items in the same order of presentation by saying them aloud and by saying "skip" whenever they did not remember the word at a given serial position. The researcher recorded the participant's responses on a prepared response sheet. Participants were not allowed to backtrack to change a previous response. Participants' responses were self-paced such that the participant pressed the space bar on the computer to begin the next trial.

\section{Results}

Responses were first scored according to strict serial recall. Separate analyses were then performed on item and order errors. In all analyses, the .05 level of significance was adopted.
Correct recall To be considered correct, words had to be recalled in their exact presentation position. The proportion of correct recall was assessed as a function of both serial position (1-5) and list type (one syllable, many neighbors; two syllables, many neighbors; two syllables, few neighbors; three syllables, few neighbors; four or five syllables, few neighbors).

In Fig. 1, recall performance is summarized as a function of list type and serial position. As is displayed in Fig. 1, the typical serial position curves are evident, and large differences emerged between all conditions except for the two twosyllable conditions, which did not differ one from each other. A $5 \times 5$ repeated measures ANOVA with list type and serial position as variables confirmed those trends. The results revealed significant main effects of serial position, $F(4,248)=$ $305.70, p<.001, \eta_{\mathrm{p}}^{2}=.83$, and word length, $F(4,248)=79.01$, $p<.001, \eta_{\mathrm{p}}^{2}=.56$. Post-hoc comparisons (Tukey HSD) confirmed that all conditions differed significantly from one another, except for the two two-syllable conditions (two-syllable words with many neighbors $[M=.50, S D=.19]$, two-syllable words with few neighbors $[M=.50, S D=.21]$ ), which did not differ. The interaction between word length condition and serial position also reached significance, $F(16,992)=2.56, p<$ $.001, \eta_{\mathrm{p}}^{2}=.04$. This interaction is not of particular theoretical interest, and simply reflects the largest effect of word length for the first serial positions (see Poirier et al., 2005, for a discussion of this interaction).

Item errors An item error was defined as a missing item (when participants said "skip") or a recalled word that was not part of the list. The proportion of item errors was computed in each of the five conditions by dividing the number of item errors by the number of items presented. As is shown in Table 1, we observed a typical word length effect: The proportion of item errors systematically increased with word length. Furthermore, we observed no substantial difference between the two two-syllable conditions. The repeated measures ANOVA revealed a significant main effect of condition, $F(4,248)=84.79, p<.001, \eta_{\mathrm{p}}^{2}=.58$. Post-hoc comparisons (Tukey HSD) confirmed that all conditions except the two two-syllable conditions differed one from the other.

Order errors An order error was computed when an item was not recalled in its correct serial position. The proportions of order errors were computed for the five conditions by dividing the total number of order errors by the total number of items recalled in each trial, regardless of the order (see, e.g., Murdock, 1976; Poirier \& Saint-Aubin, 1996; Saint-Aubin $\&$ Poirier, 2005). As can be seen in Table 1, the proportions of order errors systematically increased with word length, and there was no notable difference between the two two-syllable conditions. Accordingly, the repeated measures ANOVA was 

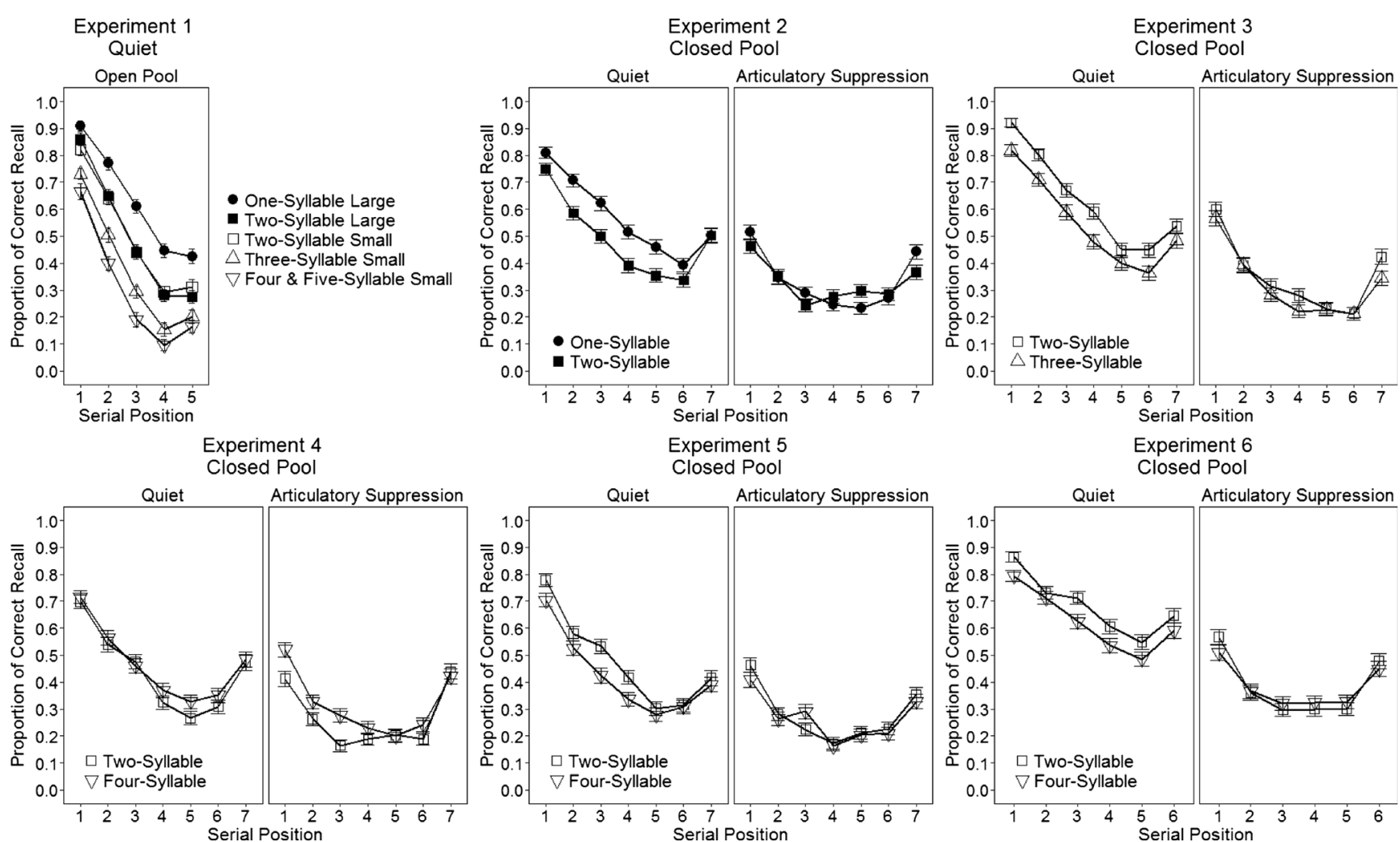

Fig. 1 Proportions of correct recall as a function of experiment, word length, neighborhood size (Exp. 1), word pool size, and interference task (Exps. 2, 3, 4, 5, and 6). Empty forms represent small neighborhood size,

significant, $F(4,248)=20.40, p<.001, \eta_{\mathrm{p}}^{2}=.25$. Post-hoc comparisons (Tukey HSD) revealed no significant differences between the two two-syllable conditions, between the twosyllable words with few neighbors and the three-syllable words, and between the three-syllable and the four-/five-syllable words. All other conditions differed significantly one from the other.

\section{Discussion}

The results of Experiment 1 revealed the presence of a large word length effect. However, the neighborhood effect was only observed when word length covaried. This was evidenced by the superior recall of one- and two-syllable words

Table 1 Proportions of item and order errors in Experiment 1

Item Errors Order Errors

\begin{tabular}{lcccc}
\hline List Type & $M$ & $S D$ & $M$ & $S D$ \\
One syllable: Large neighborhood & .24 & .15 & .18 & .18 \\
Two-syllable: Large neighborhood & .33 & .15 & .26 & .19 \\
Two-syllable: Small neighborhood & .33 & .16 & .28 & .20 \\
Three-syllable: Small neighborhood & .44 & .14 & .35 & .24 \\
Four- and five-syllable: Small neighborhood & .50 & .12 & .40 & .25
\end{tabular}

and filled forms represent large neighborhood size. Error bars represent 95\% within-participants confidence intervals computed according to Morey's (2008) procedure

with many neighbors, as compared to the other conditions with fewer neighbors but more syllables. In the critical twosyllable condition, in which neighborhood size was isolated from the influence of word length, no neighborhood effect emerged. Although the neighborhood effect has often been observed, this has not always been the case (e.g., Goh \& Pisoni, 2003; Roodenrys et al., 2002, Exp. 1). It is worth noting that Experiment 1 was primarily developed to assess the word length effect while controlling for neighborhood size. Consequently, our manipulation of neighborhood size might not have been as powerful as is usually the case in studies primarily focused on the effects of neighborhood size. For instance, Derraugh et al. (2017), who found a recall difference of about $4 \%$ between words with many and words with few neighbors, had a neighborhood difference of 12 neighbors between the two conditions, whereas our groups differed by only six neighbors.

In Experiment 1 we observed a large word length effect while controlling for neighborhood size, whereas Jalbert et al. $(2011 \mathrm{a}, \mathrm{b})$ systematically failed to observe one. This difference may have been due to our use of open word pools, whereas Jalbert and her colleagues used closed pools. It could be argued that in Jalbert and colleagues' experiments, order information predominated, whereas in the present Experiment 1 , both item and order information were called upon. In 
support of this view, our results revealed that word length accounted for two times more variance on the proportion of items than did order errors. Furthermore, although the proportions of item errors significantly differed between all word lengths, the results for proportions of order errors revealed that some conditions did not differ significantly from each other. This last finding is important because in their experiments, Jalbert et al. tested only a limited set of word lengths.

Finally, memory task differences could also account for the diverging findings between our experiment and those of Jalbert's et al. (2011a, b). In all but one experiment, Jalbert and her colleagues used an order reconstruction task in which participants responded by clicking on the items. Previous studies have shown that output modality can modulate the effects of key factors in short-term ordered recall (e.g., Beaudry, Saint-Aubin, Guérard \& Pâquet, 2017; Harvey \& Beaman, 2007). Furthermore, in the context of the word length effect, those procedural differences are very important. With an order reconstruction task and a manual response, the output times are very similar for short and long words, but they differ markedly with an immediate serial recall task and an oral recall procedure. Since the pioneering work of Cowan (1992; Cowan et al., 1992; Cowan et al., 1994a), it has been well established that the word length effect is, at least in part, due to pronunciation duration at recall. Therefore, in the experiments that follow, as in Jalbert et al. (2011a, b), we used an order reconstruction task with a manual recall procedure.

\section{Experiment 2}

As in Jalbert et al.'s (2011a, b) studies, we used an order reconstruction task with closed word pools. We contrasted one- and two-syllable words, and words from both pools had many orthographic neighbors. Furthermore, the two word pools were equated on word frequency, imageability, number of orthographic neighbors and frequency of orthographic neighbors. Articulatory suppression, was added as a further test of the neighborhood hypothesis. Under the assumption that the observed difference between the results of Experiment 1 and those of Jalbert and colleagues were due to methodological differences, the word length effect should be abolished in the present experiment that shared all key features of those of Jalbert and her colleagues. Alternatively, if results of Experiment 1 produced a genuine word length effect, it should also be observed in the present experiment, and abolished under suppression.

\section{Method}

Participants Twenty-two undergraduate students from Université de Moncton volunteered to participate for course credits. All participants reported normal or corrected-tonormal vision and were native French speakers.

Materials Two sets of French words were created, with the constraints that no words within a list could rhyme with one another. More precisely, there were ten short and ten long words (see Table 4). The short words were four-letter, monosyllabic words, and the long words were six-letter, dissyllabic words. A series of $t$ tests revealed that the short and long words did not significantly differ from one another on imageability, word frequency, and orthographic neighbor count and frequency (all $p \mathrm{~s}>.36$ ). On each trial, seven words were randomly selected from the appropriate pool of ten words (short or long), with the constraint that a word could only be used once in a list. All words were presented in black, lowercase, 28-point Arial font, in the center of the computer screen. In the articulatory suppression condition, participants were required to repeat aloud the alphabetic sequence $(a, b, c$, $d, e, f, g)$ at a rate of two letters per second during the presentation of the words. The experiment was controlled with EPrime 2.0 with a resolution of $800 \times 600$ pixels and the stimuli were presented on a $47.72 \mathrm{~cm}$ (18 in.) screen.

Pronunciation time was also measured. The 20 words were displayed in black, lowercase, 16-point Time New Roman font. Participants were digitally recorded, and the global list pronunciation time was measured using Audacity 2.1.0.

Design and procedure A $2 \times 2 \times 7$ repeated measures design was implemented with word length (short vs. long), interference (silence vs. articulatory suppression), and serial position (1-7) as variables. There were 15 experimental trials per condition (i.e., short silence, short articulatory suppression, long silence, long articulatory suppression). Conditions were randomized for each participant. Each participant completed one block of 60 experimental trials preceded by the practice of the interference task. Participants were tested individually in one experimental session lasting approximately $40 \mathrm{~min}$.

Each trial began with the presentation of the instructions for the interference task, which was presented for 1,500 ms. The word Parler ("Speak") in blue signaled the requirement of immediately beginning to repeat aloud the alphabetic sequence $(a, b, c, d, e, f, g)$ at a rate of two letters per second. Participants were instructed to stop repeating the letters when recall instructions appeared at the screen. If the word Silence ("Silence") in blue was displayed, participants had to remain quiet during the presentation of the words. Instructions were followed by the presentation of the seven to-be-remembered words that were displayed at a rate of one word per second (i.e., 1,000 ms on, $0 \mathrm{~ms}$ off) in the center of the screen. After the presentation of the last word, all words reappeared simultaneously in random order on two lines in the center of the screen. Recall was indicated in the upper part of the screen by three questions marks in blue. Participants were instructed to 
recall the words from the first to the last word that had been presented. Recall was achieved by clicking on the items with the dominant hand. Once an item was selected, its color changed from black to blue. No time limit was imposed for recall, and participants were not allowed to backtrack in order to change a previous response. Participants initiated the next trial by pressing the space bar.

On completion of the memory task, the participant's pronunciation time was measured for each word pool (i.e., short, long). The testing order of the two word pools was counterbalanced across participants. The ten words of each pool were printed on two horizontal lines (five words on each line). Participants had to read aloud each word pool ten times as fast as they could without breaks. The experimenter was present to count the number of repetitions and to signal the end of the repetitions. Participants were allowed to take a break between the two word pools.

\section{Results}

The proportion of correct recall was assessed with a $2 \times 2 \times 7$ repeated measures ANOVA, with word length (short vs. long), interference (silence vs. articulatory suppression), and serial position (1-7) as variables.

Correct recall As is shown in Fig. 1, participants were better at recalling short than at recalling long words under the quiet condition, but not under articulatory suppression. Reflecting those trends, the ANOVA revealed that recall accuracy was significantly lower for long $(M=.41, S D=.28)$ than for short $(M=.45, S D=.30)$ words, $F(1,21)=7.58, p=.012, \eta_{\mathrm{p}}^{2}=.27$, and in the articulatory suppression condition $(M=.33, S D=$ $.25)$ than in the silent condition $(M=.53, S D=.30), F(1,21)=$ $89.05, p<.001, \eta_{\mathrm{p}}^{2}=.81$. As anticipated, the main effect of serial position, $F(6,126)=44.45, p<.001, \eta_{p}^{2}=.68$, and the interaction between word length and interference, $F(1,21)=$ $4.55, \eta_{\mathrm{p}}^{2}=.18, p=.045$, were significant. More precisely, a reliable word length effect in the silent condition, $F(1,21)=$ $10.71, p=.004, \eta_{\mathrm{p}}^{2}=.34$, vanished when participants performed articulatory suppression, $F<1$. The interaction between interference and serial position, $F(6,126)=10.62, p$ $<.001, \eta_{\mathrm{p}}^{2}=.34$, and the three-way interaction, $F(6,126)=$ $3.53, p=.003, \eta_{\mathrm{p}}^{2}=.14$, were also significant. These interactions are not of any particular theoretical interest, but simply reflect the larger effect of suppression for the first serial positions and the advantage for long words under suppression for mid serial positions. Finally, the interaction between word length and serial position did not reach significant, $F<1$.

Articulation time Pronunciation time was analyzed by comparing the average reading time for the ten repetitions of short words to the reading time for the ten repetitions of long words. The results revealed that participants took significantly less time to repeat short $(M=46.46 \mathrm{~s}, S D=10.42 \mathrm{~s})$ than to repeat long $(M=56.97 \mathrm{~s}, S D=15.28 \mathrm{~s})$ words, $t(21)=3.35, p=.003$, $d=0.71$.

\section{Discussion}

The results of Experiment 2 replicated those of Experiment 1. We observed a large word length effect in the silent condition that vanished under suppression conditions. The word length effect was observed despite the use of an order reconstruction task, with a closed pool and manual recall. Those results are consistent with previous findings of the word length effect that confounded neighborhood size (e.g., Baddeley et al., 1975; Cowan et al., 2003; Poirier et al., 2005), but not with those of Jalbert et al. (2011a, b), who controlled for the number and frequency of orthographic neighbors. Even if results of Experiments 1 and 2 are clear, it could be argued that our findings are restricted to words with large neighborhoods, whereas Jalbert and colleagues abolished the word length effect with stimuli having many, few, or no orthographic neighbors. Consequently, in Experiment 3 the word length effect was assessed with words devoid of orthographic neighbors.

\section{Experiment 3}

In Experiment 3, we replicated the design of Experiment 2, but this time we contrasted two- and three-syllable words without orthographic neighbors. Assuming that the observed differences between our results and those of Jalbert et al. (2011a, b) are restricted to words with large neighborhoods, the word length effect should be abolished. However, if word length had an effect over and above that of neighborhood size, we should observe a large word length effect.

\section{Method}

Participants Twenty-two undergraduate students from Université de Moncton volunteered to participate for course credits. All participants reported normal or corrected-tonormal vision and were native French speakers. None had participated in previous experiments.

Materials, design, and procedure The design and procedure were identical to those of Experiment 2, except for the to-beremembered items. In Experiment 3 two new pools of ten French words (short and long) were created and equated on the same dimensions as in Experiment 2, except that none of them had neighbors (see Table 5). Paired $t$ tests revealed that the short and long words did not differ significantly on familiarity, imageability, or number of orthographic neighbors (all 
$p \mathrm{~s}>$.44). The short words were seven-letter, two-syllable words, and the long words were ten-letter, three-syllable words.

\section{Results}

Correct recall As can be seen in Fig. 1, performance was better for short than for long words in the control condition, but not under conditions of suppression. Overall, recall accuracy was significantly lower under suppression conditions $(M$ $=.34, S D=.24)$ than under silent conditions $(M=.59, S D=$ .27), $F(1,21)=103.87, p<.001, \eta_{\mathrm{p}}^{2}=.83$. Recall accuracy was higher for short $(M=.49, S D=.29)$ than for long $(M=$ $.43, S D=.27)$ words, $F(1,21)=15.68, p<.001, \eta_{p}^{2}=.43$, and the main effect of serial position was significant, $F(6,126)=$ $107.54, p<.001, \eta_{p}^{2}=.84$. As we anticipated, the interaction between word length and articulatory suppression was significant $F(1,21)=5.56, p=.028, \eta_{p}^{2}=.21$. More precisely, the word length effect was present in the silent condition, $F(1,21)$ $=25.54, p<.001, \eta_{\mathrm{p}}^{2}=.55$, but abolished in the articulatory suppression condition, $F=2.54, p=.15$. The interaction between interference and serial position was significant, $F(6$, 126) $=7.05, p<.001, \eta_{\mathrm{p}}^{2}=.25$, but none of the other interactions reached significance (all $F_{\mathrm{s}}<1$ ). The interaction between interference and serial position simply reflects larger suppression effects for the first serial positions and is not of particular theoretical interest in the present study.

Articulation time A $t$ test confirmed that participants took more time to repeat long words $(M=64.60 \mathrm{~s}, S D=9.86 \mathrm{~s})$ than to repeat short words $(M=49.29 \mathrm{~s}, S D=6.66 \mathrm{~s}), t(21)=$ $11.23, p<.001, d=2.39$.

\section{Discussion}

Again, the results of Experiment 3 replicated those of Experiments 1 and 2. In effect, we observed a large word length effect in the silent condition, but not under suppression conditions. The word length effect was observed despite our use of words without orthographic neighbors. These results are once again incompatible with the neighborhood hypothesis put forward by Jalbert et al. (2011a, b).

\section{Experiment 4}

The presence of a large word length effect in the first three experiments using two languages, three distinct sets of word pools, two memory tasks and two response modalities are convincing evidences of a genuine syllable-based word length effect that is independent of neighborhood effects. However, the present results raise the issue of why Jalbert et al. (2011a, b) systematically failed to observe a word length effect. One potential answer is the unusual structure of their short items than for their long items. In effect, as highlighted in the introduction of this article, the short, one-syllable words and nonwords used by Jalbert and her colleagues were not typical of the population of short one-syllable words and non-words that usually have far more neighbors. This is potentially problematic because the typicality of a word structure has been shown to affect memory performance (Freeman, Heathcote, Chalmers, \& Hockley, 2010).

To measure the typicality of a word structure, we used $n$ gram measures based on the sequence of letters in a word. More specifically, we used constrained unigram (letter), bigram (two-letter combinations), and trigram (three-letter combinations) counts and frequencies. For instance, the word grief contains five unigrams ( $g-r-i-e-f)$, four bigrams ( $g r$-ri-ieef), and three trigrams (gri-rie-ief). The constrained unigram count for the word grief refers to the average count of the five unigrams. More specifically, within the CELEX database, each word of the same length as the target word (e.g., grief) that shares the same unigram at the same position counts as one (e.g., gyrus, frost, alien, agree, scarf; Medler \& Binder, 2005). The frequency is computed in the same way, but on the basis of word frequency. Jalbert and her colleagues (2011a, b) tested their stimuli on bigram frequency and other word dimensions and found no significant differences between their short and long items. However, as can be seen in Table 2, their stimuli differed on most of the other dimensions, including the unigram, bigram, and trigram average constrained counts, which are systematically lower for short than for long words. Therefore, it can be argued that the orthographic structures of their short words were less frequent than the structures of their long words.

Before concluding that the abolition of the word length effect reported by Jalbert et al. (2011a, b) is due to the observed differences in the orthographic structures of their short and long words, the impact of this factor needed to be tested in an immediate serial order reconstruction task. More specifically, we contrasted short words with less typical structures (as measured by all six $n$-gram measures) with long words with more typical structures, while also controlling for neighborhood and all other factors. Under the assumption that Jalbert and colleagues' failure to observe a word length effect was due to word structure typicality, we predicted that the word length effect should be abolished or even reversed in the following experiment. This pattern of results should be observed despite longer pronunciation times for the long words.

\section{Method}

Participants Twenty-two undergraduate students from Université de Moncton volunteered to participate for course 
Table 2 Average constrained counts and frequencies of unigrams, bigrams, and trigrams for Jalbert et al.'s (2011a, b) experiments and Experiments 2 and 3 of the present study

\begin{tabular}{|c|c|c|c|c|c|c|c|c|c|c|c|c|c|}
\hline \multirow[t]{3}{*}{ Study } & \multirow[t]{3}{*}{ Stimuli } & \multirow{2}{*}{\multicolumn{2}{|c|}{$\frac{\text { Unigram }}{\text { Count }}$}} & \multirow{2}{*}{\multicolumn{2}{|c|}{$\begin{array}{l}\text { Unigram } \\
\text { Frequency }\end{array}$}} & \multirow{2}{*}{\multicolumn{2}{|c|}{$\frac{\text { Bigram }}{\text { Count }}$}} & \multirow{2}{*}{\multicolumn{2}{|c|}{$\frac{\text { Bigram }}{\text { Frequency }}$}} & \multirow{2}{*}{\multicolumn{2}{|c|}{$\frac{\text { Trigram }}{\text { Count }}$}} & \multirow{2}{*}{\multicolumn{2}{|c|}{$\begin{array}{l}\text { Trigram } \\
\text { Frequency }\end{array}$}} \\
\hline & & & & & & & & & & & & & \\
\hline & & Short & Long & Short & Long & Short & Long & Short & Long & Short & Long & Short & Long \\
\hline Jalbert et al. (2011a, Exps. 3 \& 5) & Words & 411 & $722^{* * *}$ & 8,477 & $3,262^{* * *}$ & 39 & $108^{* * *}$ & 1,028 & 585 & 6 & $22^{* *}$ & 138 & 184 \\
\hline Jalbert et al. (2011a, Exp. 4) & Words & 301 & $811^{* * * *}$ & 7,921 & $3,957^{* * *}$ & 35 & $159^{* * *}$ & 1,089 & 949 & 5 & $46^{* *}$ & 79 & $389^{*}$ \\
\hline $\begin{array}{l}\text { Jalbert et al. (2011b, Exp. 3; Small } \\
\text { neighborhood size) }\end{array}$ & Non-Words & 402 & 410 & 10,494 & $6,456^{* *}$ & 51 & 34 & 2,156 & $964^{*}$ & 3 & 3 & 472 & 91 \\
\hline $\begin{array}{l}\text { Jalbert et al. (2011b, Exp. 3; Large } \\
\text { neighborhood size) }\end{array}$ & Non-Words & 265 & $483^{* *}$ & 12,332 & 9,499 & 32 & $91^{* *}$ & 2,877 & 2,104 & 5 & $11^{* *}$ & 467 & 614 \\
\hline \multicolumn{14}{|l|}{ Present study } \\
\hline Exp. 2 & Words & 8,066 & $11,095^{\text {***** }}$ & 48,163 & 46,826 & 802 & $1,350^{* * *}$ & 4,431 & 4,898 & 74 & $212^{* * * *}$ & 203 & $637^{* *}$ \\
\hline Exp. 3 & Words & 8,520 & 7,583 & 34,829 & $22,801 * * *$ & 721 & 924 & 3,293 & 2,591 & 102 & 179 & 361 & 569 \\
\hline
\end{tabular}

The average constrained unigram, bigram and trigram count and frequency for Jalbert et al. (2011a, b) stimuli measures are from the MCWord database of Medler and Binder (2005; www.neuro.mcw.edu/mcword). The average constrained unigram, bigram and trigram count and frequency for the present study stimuli measures are from the Lexique database (www.lexique.org). ${ }^{*} p<.05,{ }^{* *} p<.01,{ }^{* * * *} p<.001$

credits. All participants reported normal or corrected-tonormal vision and were native French speakers. None of the participants had completed any of the previous experiments.

Materials, design, and procedure The design and procedure were identical to those used in Experiments 2 and 3. We used 10 two-syllable words (short words) and 10 four-syllable words (long words) equated on word frequency, frequency of orthographic neighbors, and count using Lexique (New et al., 2004), with the lowest $p$ value being .39. In addition, according to Lexique, the short-word constrained counts and frequencies for unigrams, bigrams, and trigrams were significantly smaller than those for long words (all $p$ s $<.01$ ) (see Table 6).

\section{Results}

Correct recall As is shown in Fig. 1, the word length effect was reversed. Overall, participants were better at recalling long $(M=.39, S D=.25)$ than at recalling short words $(M=$ $.35, S D=.23), F(1,21)=4.55, p=.045, \eta_{\mathrm{p}}^{2}=.18$, and better under silent conditions $(M=.45, S D=.25)$ than under suppression conditions $(M=.29, S D=.20), F(1,21)=71.39, p<$ $.001, \eta_{\mathrm{p}}^{2}=.77$. The main effect of serial position was significant, $F(6,126)=34.11, p<.001, \eta_{\mathrm{p}}^{2}=.62$, as well as the interaction between serial position and suppression, $F(1,21)$ $=8.61, p<.001, \eta_{\mathrm{p}}^{2}=.29$, but no other interactions reached significance, all $p \mathrm{~s}>.08$.

Articulation time As in Experiments 2 and 3, pronunciation time was analyzed. The results from the $t$ test revealed that participants were slower at repeating long words $(M=90.41 \mathrm{~s}$,
$S D=19.67 \mathrm{~s})$ than at repeating short words $(M=76.00 \mathrm{~s}, S D=$ $13.06 \mathrm{~s}), t(21)=6.84, p<.001, d=1.46$.

\section{Discussion}

As predicted, we abolished the word length effect when the short words had a less typical structure than the long words. This finding suggests that the abolition of the word length effect reported by Jalbert et al. (2011a, b) could have been due to the confounded effect of word typicality.

\section{Experiment 5}

The discovery of a powerful effect of word structure typicality prompted us to reexamine the stimuli used in our first three experiments. In developing our stimuli, we did not attempt to equate them on any of the six $n$-gram dimensions. However, as is shown in Table 2, for Experiment 2, our stimuli were equated on unigram and bigram frequency, but not on any other dimension. In Experiment 3, the stimuli differed significantly only on unigram frequency, but at the descriptive level the match between short and long words was not perfect. Consequently, in Experiment 5 we replicated the design of Experiment 4, while equating our stimuli on all $n$-gram measures in addition to the other controls.

\section{Method}

Participants Twenty-two undergraduate students from Université de Moncton volunteered to participate for course credits. All participants reported normal or corrected-to- 
normal vision and were native French speakers. None had participated in the previous experiments.

Materials, design, and procedure The design, procedure, and scoring techniques were identical to those used in Experiments 2-4. We selected 10 two-syllable words (short words) and 10 four-syllable words (long words) equated on the same dimensions as in Experiments 2 and 3. In addition, we controlled for both the constrained counts and frequencies of unigrams, bigrams, and trigrams using Lexique (New et al., 2004) (see Table 7). The $t$ tests revealed that short and long words did not differ significantly on any of these dimensions (all $p \mathrm{~s}>.17$ ).

\section{Results}

Correct recall As can be seen in Fig. 1, the word length effect was present under quiet conditions, but not under suppression conditions. Recall performance was superior for short words $(M=.38, S D=.25)$ as compared to long words $(M$ $=.35, S D=.25), F(1,21)=5.51, p=.029, \eta_{\mathrm{p}}^{2}=.21$, and performance was better under quiet conditions $(M=.45$, $S D=.26)$ than under articulatory suppression conditions $(M=.27, S D=.21), F(1,21)=114.87, p<.001, \eta_{\mathrm{p}}^{2}=.85$. The main effect of serial position was significant, $F(6$, 126) $=46.81, p<.001, \eta_{\mathrm{p}}^{2}=.69$, as well the interaction between word length and articulatory suppression, $F(1$, 21) $=4.33, p=.049, \eta_{\mathrm{p}}^{2}=.17$. More specifically, under quiet conditions the word length effect was present, $F(1$, 21) $=8.84, p=.007, \eta_{\mathrm{p}}^{2}=.30$, but it vanished under suppression conditions, $F<1$. None of the other interactions reached significance, except the interaction between articulatory suppression and serial position, $F(6,126)=$ $13.10, p<.001, \eta_{\mathrm{p}}^{2}=.38$. This interaction simply reflected the larger effect of articulatory suppression on the last serial positions.

Articulation time Participants were quicker to pronounce short $(M=55.56 \mathrm{~s}, S D=11.73 \mathrm{~s})$ than to pronounce long words $(M=73.27 \mathrm{~s}, S D=15.37 \mathrm{~s}), t(21)=9.05, p<.001, d$ $=1.93$.

\section{Discussion}

As in the first three experiments, a large word length effect was observed, and as expected, it vanished under suppression conditions. The word length effect remains after controlling for word frequency, imageability, neighborhood size measures, and word typicality measures.

\section{Experiment 6}

In Experiment 5, in the quiet condition we observed a clear word length effect at the first serial positions, but not at the last three. The lack of a word length effect at the last three serial positions could be attributed to a floor effect, or it could suggest the presence of a weak word length effect when all appropriate controls are implemented. Accordingly, we reduced the list length to six words in order to increase performance at the last serial positions.

\section{Method}

Participants Twenty-two undergraduate students from Université de Moncton volunteered to participate for course credits. All participants reported normal or corrected-tonormal vision and were native French speakers. None had participated in the previous experiments.

Materials, design, and procedure The design, procedure, stimuli, interference task, and scoring technique were identical to those used in Experiment 5, with the exception that the list length was reduced to six items.

\section{Results}

Correct recall As is shown in Fig. 1, a substantial word length was present in the control condition but was abolished under articulatory suppression. Overall, participants were better at recalling short words $(M=.53, S D=.31)$ than at recalling long words $(M=.50, S D=.29), F(1,21)=5.89, p=.024, \eta_{\mathrm{p}}^{2}=$ .22 , and performed better in the quiet condition $(M=.65, S D=$ $.28)$ than in the interference condition $(M=.38, S D=.27)$, $F(1,21)=164.06, p<.001, \eta_{\mathrm{p}}^{2}=.89$. The main effect of serial position was significant, $F(5,125)=26.48, p<.001, \eta_{p}^{2}=.56$. As in previous experiments, the interaction between word length and suppression was significant, $F(1,21)=5.00, p=$ $.036, \eta_{\mathrm{p}}^{2}=.19$. Reflecting this interaction, we observed a significant effect of word length in the control condition, $F(1,21)$ $=9.79, p=.005, \eta_{\mathrm{p}}^{2}=.32$, but not under articulatory suppression, $F<1$. The interaction between interference and serial position was significant, $F(5,125)=5.98, p<.001, \eta_{\mathrm{p}}^{2}=.22$, and simply reflects the larger effect of articulatory suppression at the last serial positions. None of the other interactions reached significance.

Articulation time The results from a $t$ test revealed that participants were slower at repeating long words $(M=66.27 \mathrm{~s}$, $S D=10.06 \mathrm{~s})$ than at repeating short words $(M=49.99 \mathrm{~s}, S D=$ $7.69 \mathrm{~s}), t(21)=14.21, p<.001, d=2.99$. 


\section{Discussion}

The results again showed a word length effect even after controlling for word frequency, imageability, orthographic neighbors, and typicality of the orthographic structure. Furthermore, for the quiet condition the word length effect was present at all serial positions. This finding suggests that the lack of a word length effect at the last three serial positions in Experiment 5 was due to a floor effect.

\section{General discussion}

The results of all six experiments are clear and easy to summarize. As expected, we observed a word length effect under quiet conditions that vanished under suppression conditions in all experiments, except Experiment 4, in which the typicality of the word structure overrode the word length effect. More precisely, we reproduced the better recall of short than of long words in Experiment 1 with an immediate serial recall task, multiple word lengths, and a large pool of English words, while controlling for neighborhood size. The results further showed the presence of large word length effects on both item and order errors. In fact, the correlation based on the mean proportions of item and order errors reported in Table 1 is almost perfect, $r=.993, p<.001$. This correlation suggests that the word length effect for item information is likely driven by the same factors as the word length effect for order information. The results of the following experiments, using small word pools, further confirmed those trends. In effect, although the methodology of those experiments mainly called upon memory for order information, the pattern of results was the same as that observed in Experiment 1. More specifically, using an order reconstruction task and French words with either many (Exp. 2) or few (Exp. 3) neighbors, we also observed a large syllable-based word length effect that vanished under conditions of suppression. In Experiment 4 we tested the hypothesis that the previous abolition of the word length effect, when neighborhood size was controlled, was due to a confounded factor: the typicality of the orthographic structure. We tested this hypothesis by contrasting short words with a less typical structure and long words with a more typical structure. As had previously been reported by Jalbert et al. (2011a, b), we abolished the word length effect. In a final test of the word length effect when orthographic neighbors and the typicality of orthographic structure were controlled for, the results again revealed the presence of a word length effect under silent conditions, but not in suppression conditions, for lists of seven (Exp. 5) and six (Exp. 6) words.

Like Jalbert et al. (2011a, b), we aimed in the present study to investigate the role of orthographic neighbors in producing the syllable-based word length effect. The original finding by
Jalbert and her team had major theoretical implications. For instance, in a recent review of the main theoretical accounts of working memory capacity limits, Oberauer, Farrell, Jarrold, and Lewandowsky (2016) cited Jalbert and colleagues' results as evidence against rehearsalbased accounts of the word length effect. Oberauer et al. also used the findings to support the hypothesis that item proprieties, such as complexity and neighborhood density, cause the word length effect (see also Lewandowsky \& Oberauer, 2008; Service, 1998). Despite the major theoretical implications of Jalbert et al.'s findings, to the best of our knowledge no published study had attempted to replicate those findings. In light of the present results, we concluded (1) that the syllable-based word length effect is a reliable, systematically observed phenomenon, even after taking neighborhood size and the typicality of the orthographic structure into account; (2) that the abolition of the word length effect in Jalbert and colleagues' studies was due to a confounded factor, the typicality of orthographic structure; and (3) that the latter point further shows the contribution of lexical factors to short-term ordered recall performance.

\section{Theoretical implications}

Taken together, our results provide unambiguous evidence that neighborhood size cannot be a complete explanation of the word length effect. However, the present results raised the issue of which factors cause the syllable-based word length effect. The two main classes of models that have been proposed are the time-based models (e.g., Baddeley \& Hitch, 1974; Baddeley et al., 1975; Brown \& Hulme, 1995; Burgess \& Hitch, 1999; Page \& Norris, 1998; Schweickert $\&$ Boruff, 1986) and the interference-based models (e.g., Brown et al., 2007; Neath \& Nairne, 1995).

As their name implies, decay is central to time-based models (e.g., Baddeley \& Hitch, 1974; Baddeley et al., 1975; Burgess \& Hitch, 1999; Poirier et al., 2005; Schweickert \& Boruff, 1986). According to these models, memory representations decay over time unless they are reactivated. Reactivation is thought to occur through either subvocal articulation processes (Baddeley et al., 1975) or attention-based processes (Baddeley, 2000; Camos, Lagner, \& Barouillet, 2009; Cowan, 1992). According to this view, long words take more time than short words to reactivate because they are longer to pronounce or because they allow less time for attentional refreshing. Under articulatory suppression, reactivation is not possible and recall performance becomes equivalent for short and long words (e.g., Baddeley, Chincotta, Stafford, \& Turk, 2002; Baddeley et al., 1975; Russo \& Grammatopoulou, 2003).

Decay-based models provide a straightforward account of all word length effects observed in the present series of 
experiments, except for Experiment 4, in which the word length effects reversed when short words with uncommon orthographic structures were used. Traditionally, within decay-based models the influence of lexical factors, such as the typicality of the orthographic structure, has been accounted for by calling upon reconstruction processes (see, e.g., Hulme et al., 1991; Schweickert, 1993; Stuart \& Hulme, 2009). According to this view, at recall, memory representations are likely to be degraded, and the degraded traces must undergo a reconstruction procedure calling upon long-term knowledge of the to-be-remembered items. Lexical factors would increase the probability of a successful trace reconstruction by increasing access to the appropriate lexical representations. For instance, high-frequency words would be recalled better than low-frequency words because the former benefit from a larger number of stored exemplars, a higher baseline level of activation, or stronger long-term associative links (Hulme et al., 1997; SaintAubin \& LeBlanc, 2005; Saint-Aubin \& Poirier, 2005; Stuart \& Hulme, 2000). Similar to the frequency effect, one could assume that words with a common orthographic structure would be recalled better than words with a less common orthographic structure because the former structures have been encountered more frequently in the language. Therefore, the lexical representations of words with a common structure would be easier to access at recall.

Interference-based models offer an alternative to the decay-based models (e.g., Brown et al., 2007; Nairne, 1990; Neath \& Nairne, 1995; Oberauer, Lewandowsky, Farrell, Jarrold, \& Greaves, 2012). Broadly speaking, these models suggest that memory performance declines as the number of elements or features increases, due to growing mutual interference (Oberauer et al., 2016). As was suggested by Oberauer et al. (2016), when the number of syllables or phonemes increase, the number of shared features among active memory representations is likely to increase. Consequently, performance would be lower for lists composed of items with more elements or features than for lists with fewer elements.

As Jalbert et al. (2011a) noted, the interference-based Scale Invariant Memory and Perceptual Learning model (SIMPLE), proposed by Brown, Neath, and Chater (2007), can account for the typical syllable-based word length effect. Broadly speaking, according to SIMPLE, list items are represented within a multidimensional space on one or more dimensions, and forgetting arises from interference between the active memory representations. Recall performance is higher for items that share fewer features or dimensions with other active representations. In other words, more-distinct items are recalled better. According to this view, lists of short words are recalled better than lists of long words, because short words are more likely to share fewer features with other list members than are long words. Therefore, short words would be more distinct and recalled better than long words. Under articulatory suppression, the number of shared features among the active memory representations would increase, leading to equivalent performance between short and long words.

SIMPLE can account for the word length effect observed in the present series of experiments. However, the results of Experiment 4 are problematic for SIMPLE, because items with an uncommon orthographic structure should be more distinct than items with a more common structure. Likewise, the neighborhood size effect challenges SIMPLE, because items with many neighbors were recalled better than those with fewer neighbors, despite the former being less distinctive. Derraugh et al. (2017) handled this issue by assuming that recall is a two-step process - that is, generating candidates in the first instance, and then choosing among the generated candidates. Words with more orthographic neighbors, because they are strongly activated, can be easier to generate, whereas words with few neighbors would be harder to generate. Here it can be assumed that words with a more common orthographic structure would be easier to generate than words with an uncommon orthographic structure, because the former might benefit from a higher baseline level of activation.

\section{Conclusion}

Overall, our results confirm the presence of a substantial syllable-based word length effect, even after controlling for word frequency, imageability, orthographic neighbors, and typicality of orthographic structure. These results are consistent with previous findings of the word length effect that have confounded neighborhood size (e.g., Baddeley et al., 1975; Schweickert \& Boruff, 1986). Furthermore, this pattern of results was observed even though short and long words were equated on neighborhood size. Therefore, on the basis of the present set of findings, we conclude that the neighborhood hypothesis proposed by Jalbert et al. (2011a, b) does not adequately account for the syllable-based word length effect. We also conclude that the abolition of the syllable-based word length effect observed in Jalbert and colleagues' experiments was due to a confounded factor of typicality of word structure.

Author note This research was supported by a Natural Sciences and Engineering Research Council of Canada undergraduate and graduate scholarship to D.G., and by a Discovery grant from the Natural Sciences and Engineering Research Council of Canada to J.St.-A. 


\section{Appendix}

Table 3 Item characteristics of the five word pools used in Experiment 1

\begin{tabular}{|c|c|c|c|c|c|c|c|c|}
\hline \multirow[t]{2}{*}{ List Type } & \multicolumn{2}{|l|}{ Freq. } & \multicolumn{2}{|l|}{ Orth. } & \multicolumn{2}{|c|}{ Orth. Freq. } & \multicolumn{2}{|l|}{ Imag. } \\
\hline & $M$ & $S D$ & $M$ & $S D$ & $M$ & $S D$ & $M$ & $S D$ \\
\hline One syllable: Small neighborhood & 22.69 & 23.91 & 8.56 & 2.77 & 54.85 & 77.23 & 541.97 & 60.80 \\
\hline Two-syllable: Large neighborhood & 19.86 & 27.91 & 6.25 & 2.17 & 13.47 & 17.31 & 532.35 & 67.13 \\
\hline Two-syllable: Small neighborhood & 17.44 & 16.81 & 0.23 & 0.50 & 0.07 & .23 & 541.86 & 59.86 \\
\hline Three-syllable: Small neighborhood & 17.36 & 28.24 & 0.09 & 0.35 & 0.01 & .05 & 527.86 & 72.02 \\
\hline Four- and five-syllable: Small neighborhood & 18.91 & 31.18 & 0.02 & 0.13 & 0.00 & .02 & 495.54 & 74.57 \\
\hline
\end{tabular}

Measures for the words frequency, for the number of orthographic neighbors and for the orthographic neighbors frequency are from the MCWord database of Medler and Binder (2005; www.neuro.mcw.edu/mcword). The measure of imageability is from the Medical Research Council Psycholinguistics database (www.psy.uwa.edu.au/mrcdatabase/uwa_mrc.htm). Freq. = word frequency; Orth. = number of orthographic neighbors; Orth. Freq. $=$ frequency of orthographic neighbors; Imag. $=$ imageability

Table 4 The short (one-syllable) and long (two-syllable) words used in Experiment 2

\begin{tabular}{|c|c|c|c|c|}
\hline Word & Freq. & Orth. & Orth. Freq. & Imag \\
\hline ages & 0.00 & 9 & 31.96 & 0.00 \\
\hline bars & 8.78 & 11 & 85.20 & 5.59 \\
\hline brin & 13.99 & 9 & 63.41 & 4.00 \\
\hline jute & 2.77 & 8 & 86.61 & 3.34 \\
\hline lacs & 8.58 & 11 & 31.12 & 5.44 \\
\hline lice & 1.22 & 10 & 142.40 & 3.45 \\
\hline vues & 17.77 & 11 & 118.29 & 4.03 \\
\hline mule & 4.26 & 9 & 34.65 & 4.23 \\
\hline sole & 1.89 & 9 & 96.54 & 4.06 \\
\hline taxe & 1.42 & 8 & 40.67 & 4.07 \\
\hline$M$ & 6.07 & 9.50 & 73.09 & 3.82 \\
\hline$S D$ & 6.03 & 1.18 & 39.16 & 1.53 \\
\hline$p$ & .77 & .53 & .36 & .64 \\
\hline boulet & 3.78 & 8 & 43.20 & 4.55 \\
\hline canots & 2.03 & 10 & 20.01 & 5.57 \\
\hline capote & 13.59 & 9 & 2.90 & 5.71 \\
\hline caries & 0.54 & 10 & 67.34 & 4.89 \\
\hline galons & 10.61 & 9 & 36.36 & 0.00 \\
\hline patins & 4.26 & 9 & 20.68 & 6.17 \\
\hline pendue & 4.12 & 9 & 69.72 & 0.00 \\
\hline rapine & 1.15 & 9 & 93.30 & 0.00 \\
\hline ravage & 0.95 & 11 & 19.54 & 3.31 \\
\hline savant & 12.3 & 8 & 169.81 & 3.66 \\
\hline$M$ & 5.33 & 9.20 & 54.29 & 3.39 \\
\hline$S D$ & 4.95 & 0.92 & 49.30 & 2.49 \\
\hline
\end{tabular}

All the measures are from the Lexique database (www.lexique.org). Freq. $=$ word frequency; Orth. $=$ number of orthographic neighbors; Orth. Freq.

$=$ frequency of orthographic neighbors; Imag. = imageability
Table 5 The short (two-syllable) and long (three-syllable) words used in Experiment 3

\begin{tabular}{|c|c|c|c|}
\hline Word & Freq & Orth. & Imag. \\
\hline voyelle & 0.47 & 0 & 5.30 \\
\hline capuche & 0.61 & 0 & 4.87 \\
\hline lexique & 0.68 & 0 & 3.38 \\
\hline dilemme & 1.28 & 0 & 2.58 \\
\hline pruneau & 1.35 & 0 & 6.12 \\
\hline orgueil & 33.24 & 0 & 2.56 \\
\hline algèbre & 2.03 & 0 & 4.02 \\
\hline fantôme & 20.74 & 0 & 5.98 \\
\hline légende & 21.49 & 0 & 3.51 \\
\hline miracle & 34.12 & 0 & 3.19 \\
\hline$M$ & 11.60 & 0.00 & 4.15 \\
\hline$S D$ & 14.24 & 0.00 & 1.33 \\
\hline$p$ & .99 & 1 & .44 \\
\hline subvention & 0.54 & 0 & 2.56 \\
\hline ordonnance & 19.66 & 0 & 3.11 \\
\hline dromadaire & 0.68 & 0 & 5.90 \\
\hline microscope & 1.35 & 0 & 6.46 \\
\hline maladresse & 8.24 & 0 & 2.91 \\
\hline tintamarre & 3.31 & 0 & 3.23 \\
\hline atmosphère & 36.15 & 0 & 3.95 \\
\hline tourbillon & 11.01 & 0 & 5.66 \\
\hline bicyclette & 23.51 & 0 & 6.86 \\
\hline maquillage & 11.08 & 0 & 6.19 \\
\hline$M$ & 11.55 & 0.00 & 4.68 \\
\hline$S D$ & 11.72 & 0.00 & 1.68 \\
\hline
\end{tabular}

All the measures are from the Lexique database (www.lexique.org). Freq. $=$ word frequency; Orth. $=$ number of orthographic neighbors; Orth. Freq.

= frequency of orthographic neighbors; Imag. = imageability 
Table 6 The short (two-syllable) and long (four-syllable) words used in Experiment 4

\begin{tabular}{|c|c|c|c|c|c|c|c|c|}
\hline Word & Freq. & Orth. & Unigr. & Unigr. Freq. & Bigr. & Bigr. Freq. & Trigr. & Trigr. Freq. \\
\hline pédezouille & 0.07 & 0 & $6,319.82$ & $15,981.75$ & 348.20 & 569.39 & 57.33 & 56.94 \\
\hline kugelhof & 0.07 & 0 & $4,408.38$ & $19,194.65$ & 214.71 & 450.49 & 10.50 & 26.88 \\
\hline flemmard & 0.47 & 0 & $5,015.75$ & $19,332.75$ & 364.71 & 725.55 & 53.50 & 55.52 \\
\hline kibboutz & 0.27 & 0 & $4,903.00$ & $12,996.85$ & 304.29 & 625.67 & 30.33 & 92.57 \\
\hline bréviaire & 1.69 & 0 & $9,091.11$ & $19,127.47$ & $1,095.38$ & $2,168.20$ & 110.00 & 273.51 \\
\hline brechtienne & 0.07 & 0 & $8,009.55$ & $18,793.18$ & $1,146.00$ & $2,212.88$ & 201.22 & 208.62 \\
\hline khamsin & 0.20 & 0 & $6,398.14$ & $18,286.73$ & 561.00 & $1,399.26$ & 40.20 & 122.68 \\
\hline chlamyde & 0.20 & 0 & $7,105.25$ & $18,769.06$ & 569.57 & $1,651.33$ & 17.67 & 8.75 \\
\hline bivouac & 2.23 & 0 & $7,150.00$ & $16,894.45$ & 757.50 & $1,512.31$ & 43.80 & 24.45 \\
\hline orfèvre & 1.35 & 0 & $6,514.86$ & $18,053.93$ & 396.50 & $1,320.59$ & 9.00 & 27.02 \\
\hline$M$ & 0.66 & 0.00 & $6,491.59$ & $17,743.08$ & 575.79 & $1,263.57$ & 57.36 & 89.69 \\
\hline$S D$ & 0.79 & 0.00 & $1,451.13$ & $1,984.59$ & 326.76 & 649.17 & 58.50 & 88.16 \\
\hline$p$ & .39 & 1 & .01 & .00 & .00 & .00 & .00 & .00 \\
\hline concubinage & 0.61 & 0 & $8,374.09$ & $25,973.71$ & $1,355.40$ & $5,051.41$ & 403.44 & $1,069.56$ \\
\hline morphogenèse & 0.00 & 0 & $7,028.33$ & $21,835.81$ & 760.55 & $2,086.80$ & 51.40 & 140.76 \\
\hline paramnésie & 0.14 & 0 & $9,970.60$ & $32,497.54$ & $1,206.67$ & $4,856.95$ & 212.88 & $1,428.24$ \\
\hline antisémite & 1.15 & 0 & $8,430.60$ & $27,439.59$ & $1,142.00$ & $2,699.89$ & 154.25 & 150.86 \\
\hline feuilletoniste & 0.34 & 0 & $6,824.64$ & $28,089.80$ & 686.92 & $2,157.94$ & 185.08 & 337.28 \\
\hline internement & 1.22 & 0 & $8,906.45$ & $27,296.01$ & $2,023.00$ & $3,703.18$ & 732.56 & $1,227.69$ \\
\hline desperado & 0.20 & 0 & $7,883.11$ & $52,135.64$ & $1,022.00$ & $13,051.71$ & 219.29 & $2,046.76$ \\
\hline nouvelleté & 0.07 & 0 & $7,921.40$ & $32,730.14$ & $1,120.56$ & $6,656.77$ & 177.38 & $1,508.47$ \\
\hline contremaîtresse & 0.27 & 0 & $6,958.13$ & $24,021.97$ & $1,252.71$ & $5,183.91$ & 358.38 & $1,427.17$ \\
\hline laborantin & 0.07 & 0 & $9,019.10$ & $29,870.96$ & $1,394.44$ & $5,317.62$ & 284.50 & 394.87 \\
\hline$M$ & 0.41 & 0.00 & $8,131.65$ & $30,189.12$ & $1,196.43$ & $5,076.62$ & 277.92 & 973.17 \\
\hline$S D$ & 0.45 & 0.00 & $1,017.98$ & $8,429.15$ & 371.14 & $3,183.47$ & 189.14 & 669.52 \\
\hline
\end{tabular}

All the measures are from the Lexique database (www.lexique.org). Freq. = word frequency; Orth. = number of orthographic neighbors; Imag. = imageability; Unigr. = Unigram count; Unigr. Freq. = Unigram frequency; Bigr. = Bigram count; Bigr. Freq. = Bigram frequency; Trigr. = Trigram count; Trigr. Freq. $=$ Trigram frequency 
Table 7 The short (two-syllable) and long (four-syllable) words used in Experiments 5 and 6

\begin{tabular}{|c|c|c|c|c|c|c|c|c|c|}
\hline Word & Freq. & Orth. & Imag. & Unigr. & Unigr. Freq. & Bigr. & Bigr. Freq. & Trigr. & Trigr. Freq. \\
\hline igloo & 0.07 & 0 & 6.78 & $7,029.00$ & $17,762.20$ & 233.00 & 408.86 & 3.67 & 0.34 \\
\hline hublot & 4.66 & 0 & 4.36 & $6,553.83$ & $25,652.77$ & 549.20 & $1,019.74$ & 64.25 & 184.32 \\
\hline chandail & 11.42 & 0 & 6.60 & $7,693.75$ & $21,592.22$ & $1,386.14$ & $4,252.75$ & 282.83 & $1,233.96$ \\
\hline grief & 2.91 & 0 & 2.20 & $6,895.20$ & $28,540.74$ & 850.50 & $2,269.92$ & 137.33 & 208.90 \\
\hline cheptel & 1.35 & 0 & 1.83 & $7,391.43$ & $28,809.45$ & 752.00 & $2,668.17$ & 69.80 & 465.09 \\
\hline espion & 4.59 & 0 & 4.62 & $7,988.67$ & $29,065.84$ & 869.60 & $4,000.77$ & 113.50 & 544.77 \\
\hline bémol & 0.81 & 0 & 4.97 & $8,937.20$ & $18,389.76$ & 649.25 & 697.83 & 114.33 & 140.55 \\
\hline frileux & 3.79 & 0 & 3.66 & $7,031.14$ & $30,796.47$ & $1,015.33$ & $3,412.01$ & 132.00 & 373.43 \\
\hline parloir & 4.19 & 0 & 3.20 & $11,420.57$ & $43,975.50$ & $1,318.33$ & $7,109.15$ & 242.40 & $2,498.08$ \\
\hline clarté & 28.24 & 0 & 3.72 & $8,313.00$ & $33,191.60$ & 754.20 & $1,705.64$ & 125.75 & 323.44 \\
\hline$M$ & 6.20 & 0.00 & 4.19 & $7,925.38$ & $27,777.66$ & 837.76 & $2,754.48$ & 128.59 & 597.29 \\
\hline$S D$ & 8.36 & 0.00 & 1.64 & $1,425.12$ & $7,712.31$ & 343.71 & $2,035.16$ & 81.97 & 749.08 \\
\hline$p$ & .95 & 1 & .63 & .64 & .50 & .17 & .81 & .31 & .70 \\
\hline partenariat & 0.07 & 0 & 2.84 & $9,765.09$ & $36,965.12$ & $1,240.20$ & $6,512.80$ & 210.00 & $1,674.00$ \\
\hline caméléon & 0.68 & 0 & 6.49 & $8,422.25$ & $29,359.77$ & 953.29 & $1,699.79$ & 48.00 & 76.31 \\
\hline cardiogramme & 0.00 & 0 & 4.36 & $7,358.33$ & $24,209.39$ & $1,016.27$ & $2,489.22$ & 130.30 & 269.93 \\
\hline individu & 19.53 & 0 & 4.51 & $6,184.00$ & $21,284.65$ & 983.86 & $1,794.18$ & 155.83 & 427.03 \\
\hline dispositif & 5.07 & 0 & 1.95 & $8,037.50$ & $31,184.52$ & 990.22 & $2,717.97$ & 201.38 & 643.79 \\
\hline aéroport & 7.91 & 0 & 4.58 & $9,230.00$ & $23,436.83$ & 433.57 & 504.37 & 81.33 & 73.64 \\
\hline climatiseur & 0.14 & 0 & 3.70 & $8,151.64$ & $23,427.24$ & 983.70 & $1,399.77$ & 203.33 & 295.82 \\
\hline inconvénient & 5.54 & 0 & 2.16 & $7,077.17$ & $16,132.35$ & $1,520.27$ & $2,283.32$ & 472.60 & 619.67 \\
\hline priorité & 4.53 & 0 & 5.00 & $10,005.25$ & $32,424.05$ & $1,508.14$ & $4,452.35$ & 158.50 & 638.04 \\
\hline mélancolie & 20.68 & 0 & 3.01 & $7,821.20$ & $16,802.44$ & 870.22 & $1,605.71$ & 95.75 & 173.13 \\
\hline$M$ & 6.42 & 0.00 & 3.86 & $8,205.24$ & $25,522.64$ & $1,049.97$ & $2,545.95$ & 175.70 & 489.14 \\
\hline$S D$ & 7.73 & 0.00 & 1.40 & $1,202.96$ & $6,814.90$ & 316.64 & $1,735.86$ & 117.90 & 471.31 \\
\hline
\end{tabular}

All the measures are from the Lexique database (www.lexique.org). Freq. = word frequency; Orth. = number of orthographic neighbors; Imag. = imageability; Unigr. $=$ Unigram count; Unigr. Freq. $=$ Unigram frequency; Bigr. $=$ Bigram count; Bigr. Freq. $=$ Bigram frequency; Trigr. $=$ Trigram count; Trigr. Freq. = Trigram frequency

\section{References}

Allen, R., \& Hulme, C. (2006). Speech and language processing mechanisms in verbal serial recall. Journal of Memory and Language, 55, 64-88. https://doi.org/10.1016/j.jml.2006.02.002

Baddeley, A. D. (2000). Short-term and working memory. In E. Tulving, \& F. I. M. Craik (Eds.), The Oxford handbook of memory (pp. 77 92). New York: Oxford University Press.

Baddeley, A. D., Chincotta, D., Stafford, L., \& Turk, D. (2002). Is the word length effect in STM entirely attributable to output delay? Evidence from serial recognition. Quarterly Journal of Experimental Psychology, 55A, 353-369. https://doi.org/10.1080/ 02724980143000523

Baddeley, A. D., \& Hitch, G. J. (1974). Working memory. In G. A. Bower (Ed.), The psychology of learning and motivation: Advances in research and theory (Vol. 8, pp. 47-90). New York: Academic Press. https://doi.org/10.1016/S0079-7421(08)60452-1

Baddeley, A. D., Thomson, N., \& Buchanan, M. (1975). Word length and the structure of short-term memory. Journal of Verbal Learning and Verbal Behavior, 14, 575-589. https://doi.org/10.1016/S00225371(75)80045-4

Beaman, C. P., Neath, I., \& Surprenant, A. M. (2008). Modeling distributions of immediate memory effects: No strategies needed? Journal of Experimental Psychology: Learning, Memory, and
Cognition, 34, 219-229. https://doi.org/10.1037/0278-7393.34.1. 219

Beaudry, O., Saint-Aubin, J., Guérard, K., \& Pâquet, M. (2017). Are lexical factors immune to response modality in backward recall? The effects of imageability and word frequency. Canadian Journal of Experimental Psychology. https://doi. org/10.1037/cep0000126

Brown, G. D. A., \& Hulme, C. (1995). Modeling item length effects in memory span: No rehearsal needed? Journal of Memory and Language, 34, 594-621. https://doi.org/10.1006/jmla.1995.1027

Brown, G. D. A., Neath, I., \& Chater, N. (2007). A temporal ratio model of memory. Psychological Review, 114, 539-576. https://doi.org/10. 1037/0033-295X.114.3.539

Burgess, N., \& Hitch, G. J. (1999). Memory for serial order: A network model of the phonological loop and its timing. Psychological Review, 106, 551-581. https://doi.org/10.1037/0033-295X.106.3.551

Camos, V., Lagner, P., \& Barrouillet, P. (2009). Two maintenance mechanisms of verbal information in working memory. Journal of Memory and Language, 61, 457-469. https://doi.org/10.1016/j. jm1.2009.06.002

Clarkson, L., Roodenrys, S., Miller, L. M., \& Hulme, C. (2017). The phonological neighbourhood effect on short-term memory for order. Memory, 25, 391-402. https://doi.org/10.1080/09658211.2016. 1179330 
Coltheart, M., Besner, D., Jonasson, J. T., \& Davelaar, E. (1979). Phonological encoding in the lexical decision task. Quarterly Journal of Experimental Psychology, 31A, 489-507. https://doi. org/10.1080/14640747908400741

Cowan, N. (1992). Verbal memory span and the timing of spoken recall. Journal of Memory and Language, 31, 668-684. https://doi.org/10. 1016/0749-596X(92)90034-U

Cowan, N. (1995). Attention and memory: An integrated framework. New York: Oxford University Press.

Cowan, N., Baddeley, A. D., Elliott, E. M., \& Norris, J. (2003). List composition and the word length effect in immediate recall: A comparison of localist and globalist assumptions. Psychonomic Bulletin \& Review, 10, 74-79. https://doi.org/10.3758/BF03196469

Cowan, N., Day, L., Saults, J. S., Keller, T. A., Johnson, T., \& Flores, L. (1992). The role of verbal output time in the effects of word length on immediate memory. Journal of Memory and Language, 31, 117. https://doi.org/10.1016/0749-596X(92)90002-F

Cowan, N., Keller, T. A., Hulme, C., Roodenrys, S., McDougall, S., \& Rack, J. (1994a). Verbal memory span in children: Speech timing clues to the mechanisms underlying age and word length effects. Journal of Memory and Language, 33, 234-250. https://doi.org/ 10.1006/jmla. 1994.1012

Cowan, N., Wood, N. L., \& Borne, D. N. (1994b). Reconfirmation of the short-term storage concept. Psychological Science, 5, 103-106. https://doi.org/10.1111/j.1467-9280.1994.tb00639.x

Derraugh, L. S., Neath, I., Surprenant, A. M., Beaudry, O., \& SaintAubin, J. (2017). The effect of lexical factors on recall from working memory: Generalizing the neighborhood size effect. Canadian Journal of Experimental Psychology, 71, 23-31. https://doi.org/10. 1037/cep0000098

Freeman, E., Heathcote, A., Chalmers, K., \& Hockley, W. (2010). Item effects in recognition memory for words. Journal of Memory and Language, 62, 1-18. https://doi.org/10.1016/j.jml.2009.09.004

Glanc, G., \& Greene, R. (2012). Orthographic distinctiveness and memory for order. Memory, 20, 865-871. https://doi.org/10.1080/ 09658211.2012 .710638

Goh, W. D., \& Pisoni, D. B. (2003). Effects of lexical competition on immediate memory span for spoken words. Quarterly Journal of Experimental Psychology, 56A, 929-954. https://doi.org/10.1080/ 02724980244000710

Guérard, K., \& Saint-Aubin, J. (2012). Assessing the effect of lexical variables in backward recall. Journal of Experimental Psychology: Learning, Memory, and Cognition, 38, 312-324. https://doi.org/10. 1037/a0025481

Guérard, K., Saint-Aubin, J., Burns, S. C., \& Chamberland, C. (2012). Revisiting backward recall and benchmark memory effects: A reply to Bireta et al. (2010). Memory \& Cognition, 40, 388-407. https:// doi.org/10.3758/s13421-011-0156-2

Harvey, A. J., \& Beaman, C. P. (2007). Input and output modality effects in immediate serial recall. Memory, 15, 693-700. https://doi.org/10. 1080/09658210701644677

Hulme, C., Maughan, S., \& Brown, G. D. A. (1991). Memory for familiar and unfamiliar words: Evidence for a long-term memory contribution to short-term memory span. Journal of Memory and Language, 30, 685-701. https://doi.org/10.1016/0749-596X(91)90032-F

Hulme, C., Roodenrys, S., Schweickert, R., Brown, G. D. A., Martin, S., \& Stuart, G. (1997). Word-frequency effects on short-term memory tasks: Evidence for a redintegration process in immediate serial recall. Journal of Experimental Psychology: Learning, Memory, and Cognition, 23, 1217-1232.

Hulme, C., Silvester, J., Smith, S., \& Muir, C. (1986). The effects of word length on memory for pictures: Evidence for speech coding in young children. Journal of Experimental Child Psychology, 41, 61-75. https://doi.org/10.1016/0022-0965(86)90051-2

Hulme, C., Thomson, N., Muir, C., \& Lawrence, A. (1984). Speech rate and the development of short-term memory span. Journal of
Experimental Child Psychology, 38, 241-253. https://doi.org/10. 1016/0022-0965(84)90124-3

Jalbert, A., Neath, I., Bireta, T. J., \& Surprenant, A. M. (2011a[a]). When does length cause the word length effect? Journal of Experimental Psychology: Learning, Memory, and Cognition, 37, 338-353. https://doi.org/10.1037/a0021804

Jalbert, A., Neath, I., \& Surprenant, A. M. (2011b[b]). Does length or neighborhood size cause the word length effect? Memory \& Cognition, 39, 1198-1210. https://doi.org/10.3758/s13421-0110094-Z

LaPointe, L. B., \& Engle, R. W. (1990). Simple and complex word spans as measures of working memory capacity. Journal of Experimental Psychology: Learning, Memory, and Cognition, 16, 1118-1133. https://doi.org/10.1037/0278-7393.16.6.1118

Lewandowsky, S., \& Oberauer, K. (2008). The word-length effect provides no evidence for decay in short-term memory. Psychonomic Bulletin \& Review, 15, 875-888. https://doi.org/10.3758/PBR.15.5. 875

Longoni, A. M., Richardson, J. T., \& Aiello, A. (1993). Articulatory rehearsal and phonological storage in working memory. Memory \& Cognition, 21, 11-22. https://doi.org/10.3758/BF03211160

Lovatt, P., Avons, S. E., \& Masterson, J. (2000). The word-length effect and disyllabic words. Quarterly Journal of Experimental Psychology, 53A, 1-22. https://doi.org/10.1080/ 027249800390646

Luce, P. A., \& Pisoni, D. B. (1998). Recognizing spoken words: The neighborhood activation model. Ear and Hearing, 19, 1-36.

Medler, D. A., \& Binder, J. R. (2005). MCWord: An on-line orthographic database of the English Language Retrieved from www.neuro.mcw. edu/moword/

Mora, G., \& Camos, V. (2013). Two systems of maintenance in verbal working memory: Evidence from the word length effect. PLoS ONE, 8, e70026. https://doi.org/10.1371/journal.pone.0070026

Morey, R. D. (2008). Confidence intervals from normalized data: A correction to Cousineau (2005). Tutorial in Quantitative Methods for Psychology, 4, 61-64. https://doi.org/10.20982/tqmp.04.2.p061

Morra, S. (2015). How do subvocal rehearsal and general attentional resources contribute to verbal short-term memory span? Frontiers in Psychology, 6, 145. https://doi.org/10.3389/fpsyg.2015.00145

Murdock, B. B. (1976). Item and order information in short-term serial memory. Journal of Experimental Psychology: General, 105, 191216. https://doi.org/10.1037/0096-3445.105.2.191

Nairne, J. S. (1990). A feature model of immediate memory. Memory \& Cognition, 18, 251-269. https://doi.org/10.3758/BF03213879

Nairne, J. S., Neath, I., \& Serra, M. (1997). Proactive interference plays a role in the word-length effect. Psychonomic Bulletin \& Review, 4, 541-545. https://doi.org/10.3758/BF03214346

Neath, I. (1997). Modality, concreteness, and set-size effects in a free reconstruction of order task. Memory \& Cognition, 25, 256-263. https://doi.org/10.3758/BF03201116

Neath, I., Bireta, T. J., \& Surprenant, A. M. (2003). The time-based word length effect and stimulus set specificity. Psychonomic Bulletin \& Review, 10, 430-434. https://doi.org/10.3758/BF03196502

Neath, I., \& Nairne, J. S. (1995). Word-length effects in immediate memory: Overwriting trace decay theory. Psychonomic Bulletin \& Review, 2, 429-441. https://doi.org/10.3758/BF03210981

New, B., Pallier, C., Brysbaert, M., \& Ferrand, L. (2004). Lexique 2: A new French lexical database. Behavior Research Methods, Instruments, \& Computers, 36, 516-524. https://doi.org/10.3758/ BF03195598

Oberauer, K., Farrell, S., Jarrold, C., \& Lewandowsky, S. (2016). What limits working memory capacity? Psychological Bulletin, 142, 758 799. https://doi.org/10.1037/bul0000046

Oberauer, K., Lewandowsky, S., Farrell, S., Jarrold, C., \& Greaves, M. (2012). Modeling working memory: An interference model of 
complex span. Psychonomic Bulletin \& Review, 19, 779-819. https://doi.org/10.3758/s13423-012-0272-4

Page, M. P. A., \& Norris, D. (1998). The primacy model: A new model of immediate serial recall. Psychological Review, 105, 761-781. https://doi.org/10.1037/0033-295X.105.4.761-781

Poirier, M., \& Saint-Aubin, J. (1996). Immediate serial recall, word frequency, item identity and item position. Canadian Journal of Experimental Psychology, 50, 408-412. https://doi.org/10.1037/ 1196-1961.50.4.408

Poirier, M., Schweickert, R., \& Oliver, J. (2005). Silent reading rate and memory span. Memory, 13, 380-387. https://doi.org/10.1080/ 09658210344000440

Roodenrys, S. (2009). Explaining phonological neighbourhood effects in short-term memory. In A. S. C. Thorn \& M. P. A. Page (Eds.), Interactions between short-term and long-term memory in the verbal domain (pp. 177-197). New York: Psychology Press.

Roodenrys, S., Hulme, C., Lethbridge, A., Hinton, M., \& Nimmo, L. M. (2002). Word-frequency and phonological-neighborhood effects on verbal short-term memory. Journal of Experimental Psychology: Learning, Memory, and Cognition, 28, 1019-1034. https://doi.org/ 10.1037/0278-7393.28.6.1019

Russo, R., \& Grammatopoulou, N. (2003). Word length and articulatory suppression affect short-term and long-term recall tasks. Memory \& Cognition, 31, 728-737. https://doi.org/10.3758/BF03196111

Saint-Aubin, J., \& LeBlanc, J. (2005). Word frequency effects in immediate serial recall of pure and mixed lists: Tests of the associative link hypothesis. Canadian Journal of Experimental Psychology, 59, 219-227. https://doi.org/10.1037/h0087477

Saint-Aubin, J., \& Poirier, M. (2005). Word frequency effects in immediate serial recall: Item familiarity and item co-occurrence have the same effect. Memory, 13, 325-332. https://doi.org/10.1080/ 09658210344000369
Schweickert, R. (1993). A multinomial processing tree model for degradation and redintegration in immediate recall. Memory \& Cognition, 21, 168-175. https://doi.org/10.3758/BF03202729

Schweickert, R., \& Boruff, B. (1986). Short-term memory capacity: Magic number or magic spell? Journal of Experimental Psychology: Learning, Memory, and Cognition, 12, 419-425. https://doi.org/10.1037/0278-7393.12.3.419

Service, E (1998). The effect of word length on immediate serial recall depends on phonological complexity, not articulatory duration. Quarterly Journal of Experimental Psychology, 51A, 283-304. https://doi.org/10.1080/027249898391639

Stuart, G., \& Hulme, C. (2000). The effects of word co-occurrence on short-term memory: Associative links in long-term memory affect short-term memory performance. Journal of Experimental Psychology: Learning, Memory, and Cognition, 26, 796-802. https://doi.org/10.1037/0278-7393.26.3.796

Stuart, G. P., \& Hulme, C. (2009). Lexical and semantic influences on immediate serial recall: A role for redintegration. In A. S. C. Thorn \& M. P. A. Page (Eds.), Interactions between short-term and longterm memory in the verbal domain (pp. 157-176). New York: Psychology Press.

Walker, I., \& Hulme, C. (1999). Concrete words are easier to recall than abstract words: Evidence for a semantic contribution to short-term serial recall. Journal of Experimental Psychology: Learning, Memory, and Cognition, 25, 1256-1271. https://doi.org/10.1037/ 0278-7393.25.5.1256

Watkins, O. C., \& Watkins, M. J. (1977). Serial recall and the modality effect: Effects of word frequency. Journal of Experimental Psychology: Human Learning and Memory, 3, 712-718. https:// doi.org/10.1037/0278-7393.3.6.712

Wilson, M., \& Emmorey, K. (1998). A "word length effect" for sign language: Further evidence for the role of language in structuring working memory. Memory \& Cognition, 26, 584-590. https://doi. org/10.3758/BF03201164 